\title{
Ibrutinib-induced chronic demyelinating polyneuropathy in a 65-year-old man with chronic lymphoid leucosis: A clinical case
}

\author{
N.A. Suponeva, D.A. Grishina, M.A. Piradov \\ Research Center of Neurology, Moscow, Russia
}

\begin{abstract}
Relevance. Most of oncological patients undergo chemotherapy, which has a wide range of various toxic reactions including polyneuropathy. Ibrutinib is a relatively new medicine with a few side effects associated with peripheral polyneuropathy. Demyelinating polyneuropathy induced by this drug is not yet defined in scientific literature.

Methods. The paper describes the first case of demyelinating polyneuropathy associated with ibrutinib in a 65-yearold man with chronic lymphoid leucosis. The authors carried out clinical assessment, laboratory and instrumental examinations.

Results. Ibrutinib administration was followed by chronic sensorimotor distal polyneuropathy. The changes measured in nerve conduction studies (NCS) corresponded to chronic inflammatory demyelinating polyneuropathy (CIDP) electrophysiological criteria (EFNS/PNS, 2010). The positive aspect of the described clinical case is that polyneuropathy regressed almost completely after a dose reduction and subsequent drug discontinuation. The second NCS made 5 months after a dose reduction showed an increase in compound motor action potential (CMAP) and nerve conduction velocities (NCV); however, normal values were not reached.

Conclusion. This report on demyelinating neuropathy associated with ibrutinib requires further study of the drug effects. The below clinical description is of great interest since most of polyneuropathies associated with chemotherapy are axonal, but not demyelinating.
\end{abstract}

Keywords: lymphoproliferative diseases, chemotherapy, chemotherapy-induced neuropathy, ibrutinib, chronic demyelinating polyneuropathy, NCV, spontaneous regress

\section{INTRODUCTION}

Chemotherapy is a uniform method of treatment for a large number of oncological diseases, which form one of the main causes of morbidity and mortality in the world. However, along with high efficiency, this type of therapy has a wide range of side effects, which significantly impair the patients' quality of life, demand correction of doses of the used drugs, delay the succession of courses or cease the treatment completely, involve additional costs for diagnostics and rehabilitation (1-3). Analysis and prevention of chemotherapy side effects is undoubtedly of great medical, social and economic importance; it is an obviously urgent problem in modern medical science.

According to the USA National Cancer Institute, neurotoxicity together with myelosupression and renal failure is one of the most widespread dose-depending undesirable effects of chemotherapy. Besides, peripheral neuromotor apparatus lesion, considering hemo-neural barrier insufficiency, occurs most commonly (1-6).

This paper describes a case of demyelinating sensorimotor polyneuropathy in a patient with chronic lymphoid leucosis associated with ibrutinib administration.

\section{CLINICAL CASE}

A 65-year-old patient, a retired man, referred to the outpatient department of the Research Center of Neurology (Moscow, Russia) in July 2016 complaining of weakness in feet and awkwardness in wrists, numbness in fingers, shins and feet, and lack of confidence when walking. 
The patient's anamnesis showed that since 2008 he was followed up by oncohematologist for the diagnosis "chronic lymphocytic leukemia, stage B, the state after a course of leukeran and fludarabine (LF) therapy, 5 courses of chemotherapy with fludarabine, cyclophosphamide and rituximab (FCR), 10 courses of rituximab and bortezomib (RB) therapy, remission". In 2008-2009 within a course of chemotherapy, the patient received leukeran and fludarabine. In 2010-2011 he underwent 5 courses according to FCR scheme. This treatment was followed by a 1-year remission. A recurrence of chronic lymphocytic leukemia was detected in 2012; additional 10 courses of chemotherapy, which were carried out according to the RB treatment regimen in 2012-2014, led to stabilization. The patient had no any neurological complaints against the background of the above chemotherapeutic cycles, his state was satisfactory. At the end of 2015 (on 16.12.2015), it was decided to switch to ibrutinib $420 \mathrm{mg}$ per day. In May 2016 (i.e. 5 months after the beginning of ibrutinib administration), the patient began to feel slow steady increase of polyneuritic sensitive and motor disturbances. He was diagnosed with toxic polyneuropathy at the place of his residence and prescribed neurometabolic therapy, which was ineffective. In June 2016 (6 months of ibrutinib therapy, 1 month after the beginning of neurologic disorders), the oncohematologist reduced the dose of ibrutinib to $280 \mathrm{mg}$ a day, taking into account the progressive character of polyneuropathy.

The patient was examined at our site one month after the drug dose reduction, which helped to stabilize his state. The patient denied alcohol intake, aggravated hereditary anamnesis, and accompanying diabetes mellitus.

The results of the general examination were as follows: normosthenic constitution (weight -75 $\mathrm{kg}$, height $-170 \mathrm{~cm}$ ), no symptoms of edema, no rash and other skin lesions, no bone deformations.

The neurological presentation in July 2016: the patient was alert, attentive and oriented; the speech was clear and fluent with good repetition, comprehension and naming; there were no meningeal signs. Cranial nerves were intact. Examination revealed distant symmetric peripheral quadriparesis with a decrease in strength in the ulnar group of arm muscles to Grade 4 of Medical Research Coun- cil (MRC) scale (the right side was slightly worse), in extensors and flexors of the feet and toes - to Grade 3 of MRC scale. In other groups of muscles (the muscles of the shoulder girdle, the extensors of wrists and fingers, the median group of arm muscles, the muscles of shin flexors and extensors) the strength was sufficient. The patient stood on his toes and heels with difficulty; at the same time, he squatted down and stood up quite satisfactory. Muscle bulk was normal, muscle tone was decreased. Fasciculations were absent. Tendon reflexes were symmetric: $\mathrm{m}$. biceps brachii - brisk, styloradial - low, knee - brisk, ankles - absent. There were no pathological reflexes and tension symptoms. Coordination tests were uncertain. In Romberg's test with open eyes, the patient stood steadily, with closed eyes - reeled (sensitive ataxia). There was a painful hyposthesia of the distal polyneuritic type. The position and vibration senses were lowered in toes. The light touch sense was reduced in the distal parts of legs. Thermoesthesia was not changed. Pelvic organ functions were not disturbed. There was symmetric steppage gait when walking, but the man walked without support. The higher cortical functions corresponded to the functions of his age.

The additional examinations and their results were the following:

- Electrophoresis of serum and urine protein with immunofixation: no pathological monoclonal secretion was revealed;

- Antibodies to GM1 gangliosides: GM2-GM3GM4; GD1a, GD1b, GD2-GD3, GT1a, GT1b, GQ1b, sulfatides were negative;

- Electrophysiological study included needle electromyography and nerve conduction studies (NCS). NCS revealed rough generalized minimum asymmetric sensorimotor neural level of lesion of initially demyelinating character; it was much more expressed in the lower extremities. In studying the motor nerve fibers of arms, we registered conduction blocks of different degree of manifestation in the areas atypical for compression. In studying the motor and sensory nerves of legs, there were no registered responses of compound motor action potential (CMAP) and compound sensory action potential (CSAP). In studying the distal muscle of the leg (m.tibialis anterior dex.) by a needle electrode at rest, single denervation activity of muscle fibers 


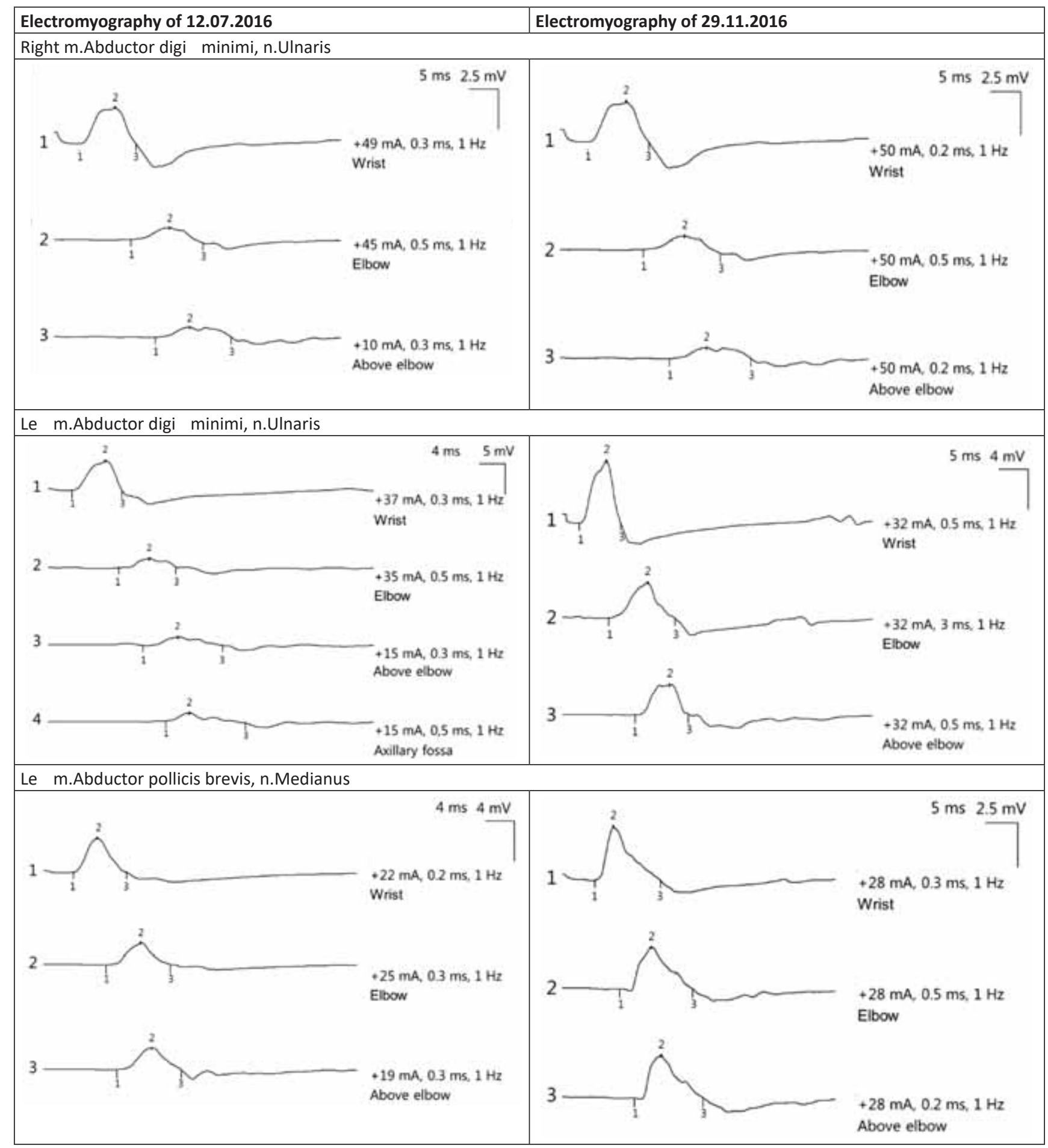

FIGURE 1. Motor responses recorded by electromyography of motor fibers of the patient's hand nerves in the initial examination (12.07.2016) and 4 months later (29.11.2016).

Note: $\mathrm{m}$.Abductor digiti minimi - the muscle abducting the little finger; $\mathrm{m}$.Abductor pollicis brevis - the short muscle abducting the thumb; n.Ulnaris - ulnar nerve; n.Medianus - median nerve.

was registered; the analysis of parameters of motor unit potentials showed signs of re-innervation (Fig. 1, Table 1).

The data obtained during NCS corresponded to neurophysiological criteria of chronic inflammatory demyelinating polyneuropathy (European Fed- eration of the Neurological Societies - EFNS), 2010 (7).

- Ultrasonography of nerves (spinal C5-Th1, branches of the brachial plexus, median and elbow nerves) did not show any change of the cross-section area at all the levels of the study. 
TABLE 1. Parameters of electromyography of motor and sensory nerves of the patient's upper and lower limbs (the study conducted on 12.07.2016)

a) Motor nerve conduc on velocity (MNCV)

\begin{tabular}{|c|c|c|c|c|c|c|}
\hline$S$ mula on site & $\begin{array}{l}\text { Latency of } \\
\text { M-response, } \\
\text { ms }\end{array}$ & $\begin{array}{c}\text { Amplitude of } \\
\text { M-response, } \\
\mathrm{mV}\end{array}$ & $\begin{array}{c}\text { Dura on of } \\
\text { M-response, } \\
\text { ms }\end{array}$ & $\begin{array}{c}\text { Area of } \\
\text { M-response, } \\
\mathrm{mV} \times \mathrm{ms}\end{array}$ & $\begin{array}{l}\mathrm{MNCV}, \\
\mathrm{ms}\end{array}$ & Comment \\
\hline \multicolumn{7}{|c|}{ Right m.Abductor digiti minimi, n.Ulnaris, C8-T1 } \\
\hline wrist & $4.45(\mathrm{~N}<3.0)$ & $2.28(\mathrm{~N}>6.0)$ & 9.86 & 13.1 & & \\
\hline $4 \mathrm{~cm}$ below elbow joint & 13.4 & 0.771 & 12.5 & 4.6 & $22.2(\mathrm{~N}>50)$ & $\begin{array}{c}\text { Forearm CB*, } \\
70 \% \text { of amplitude }\end{array}$ \\
\hline above elbow & 17.7 & 0.643 & 13.3 & 5.0 & $28.5(\mathrm{~N}>50)$ & \\
\hline \multicolumn{7}{|c|}{ Left m.Abductor digiti minimi, n.Ulnaris, C8-T1 } \\
\hline wrist & $3.75(\mathrm{~N}<3.0)$ & $4.69(\mathrm{~N}>6.0)$ & 7.6 & 20.1 & & \\
\hline $4 \mathrm{~cm}$ below elbow joint & 10.8 & 1.5 & 11.91 & 6.9 & $29.8(N>50)$ & $\begin{array}{l}\text { Forearm Mw } \\
\text { Dispersion }\end{array}$ \\
\hline Above elbow & 14.6 & 1.45 & 12.1 & 8.2 & $34.1(\mathrm{~N}>50)$ & \\
\hline Axillary fossa & 18.1 & 1.32 & 12.3 & 5.4 & $28.6(\mathrm{~N}>50)$ & \\
\hline \multicolumn{7}{|c|}{ Right m.Abductor pollicis brevis, n.Medianus, C8-T1 } \\
\hline wrist & $4.95(\mathrm{~N}<3.5)$ & $5.66(\mathrm{~N}>5.0)$ & 8.3 & 26.1 & & \\
\hline elbow & 10.1 & 5.09 & 9.05 & 23.5 & $40.8(N>50)$ & \\
\hline above elbow & 12.3 & 5.04 & 9.2 & 23.6 & $54.5(\mathrm{~N}>50)$ & \\
\hline \multicolumn{7}{|c|}{ Left m.Abductor pollicis brevis, n.Medianus, C8-T1 } \\
\hline wrist & $4.7(\mathrm{~N}<3.5)$ & $4.53(\mathrm{~N}>5.0)$ & 8.5 & 18.1 & & \\
\hline elbow & 10.1 & 2.79 & 10.2 & 12.1 & $39.2(N>50)$ & $\begin{array}{c}\text { "Possible" } \\
\text { forearm CB, 38\% } \\
\text { of amplitude }\end{array}$ \\
\hline above elbow & 11.9 & 2.86 & 10.1 & 13.1 & $72.3(\mathrm{~N}>50)$ & \\
\hline \multicolumn{7}{|c|}{ Right m.Tibialis anterior, n.Peroneus profundus, L4-S1 } \\
\hline head of $\mathrm{f}$ bular & 2.54 & $1.03(\mathrm{~N}>3.5)$ & 13.6 & 4.8 & & \\
\hline popliteal fossa & 5.61 & 0.818 & 13.2 & 4.9 & $32.6(\mathrm{~N}>40)$ & \\
\hline \multicolumn{7}{|c|}{ Right m.Abductor hallucis, n.Tibialis, L5-S1 } \\
\hline medial malleolus & & 0 & & & & \\
\hline \multicolumn{7}{|c|}{ Left m.Abductor hallucis, n.Tibialis, L5-S1 } \\
\hline medial malleolus & & 0 & & & & \\
\hline \multicolumn{7}{|c|}{ Right m.Extensor digitorum brevis, n.Peroneus profundus, L4-S1 } \\
\hline ankle joint & & 0 & & & & \\
\hline
\end{tabular}

b) Sensor nerve conduc on velocity (SNCV)

\begin{tabular}{|c|c|c|c|}
\hline$S$ mula on site & $\begin{array}{c}\text { Latency of } \\
\text { S-response, ms }\end{array}$ & $\begin{array}{c}\text { Amplitude of } \\
\text { S-response, } \mu \mathrm{V}\end{array}$ & $\mathrm{SNCV}, \mathrm{ms}$ \\
\hline \multicolumn{4}{|l|}{ Right $\mathrm{n}$. Medianus II } \\
\hline wrist & $3.28(\mathrm{~N}<3.0)$ & $0.7(\mathrm{~N}>15.0)$ & $50.3(N>50)$ \\
\hline \multicolumn{4}{|l|}{ Left $\mathrm{n}$. Medianus II } \\
\hline wrist & $3.6(\mathrm{~N}<3.0)$ & $1.4(\mathrm{~N}>15.0)$ & $40.3(N>50)$ \\
\hline \multicolumn{4}{|c|}{ Right n.Peroneus superficialis, L4-S1 } \\
\hline Middle third of lower leg & & 0 & \\
\hline \multicolumn{4}{|c|}{ Left n.Peroneus superficialis, L4-S1 } \\
\hline Middle third of lower leg & & 0 & \\
\hline
\end{tabular}

Note: M-response - motor response, S-response - sensor response, CB - conduc on block, N-norm, n.Medianus - median nerve,

n.Ulnaris - ulnar nerve, n.Peroneus profundus - deep f bular nerve, $n$.Tibialis - bial nerve, n.Peroneus superf cialis - superf cial $f$ bular nerve, m.Abductor digi minimi - the muscle abduc ng the li le f nger, m.Abductor pollicis brevis - the short muscle abduc ng the thumb, m.Tibialis anterior - anterior bial muscle, m.Abductor hallucis - the muscle abduc ng the great toe, m. Extensor digitorum brevis - the short muscle extending toes.

* Conduc on block criteria are taken from previous studies (26)

Thus, the neurological examination of the patient revealed clinical signs of sensorimotor distal polyneuropathy. The neurophysiological examina- tion confirmed the generalized sensorimotor neural level of lesion and specified the nature of the lesion as initially demyelinating. Anamnestic data showed 
convincing interrelation between the beginning of ibrutinib administration and development of polyneuropathy. The patient was diagnosed "Ibrutinib-associated chronic demyelinating polyneuropathy". Recommendations included dynamic observation and a rehabilitation course (including kinesiotherapy, wearing of orthoses).

At the re-examination conducted at the end of November 2016 (4 months after the initial examination, 5 months after ibrutinib dose reduction), the patient felt stronger in wrists, mentioned insignificant reduction of sensitive disturbances and improvement of stability when walking. The second NCS showed positive dynamics as compared with the previous examination:

- In examining the right ulnar nerve, there was a reduction of conduction block on to the forearm and an increase in motor conduction velocity (CV) at this level from 22 to $34 \mathrm{~m} / \mathrm{s}$ was noted (the norm is more than $50 \mathrm{~m} / \mathrm{s}$ );

- In examining the left ulnar nerve, we registered a significant increase in distal CMAP - from 4.7 to $6.35 \mathrm{mV}$ (the norm is more than 6), a reduction of conduction block from $68 \%$ to $42 \%$ (not registered in the norm), and an increase in sensor $\mathrm{CV}$ from 30 to $44 \mathrm{~m} / \mathrm{s}$ (the norm more than $50 \mathrm{~m} / \mathrm{s}$ );

- In examining the right deep fibular nerve (a branch of the tibialis anterior muscle), there was an increase in the M-response - from 1.03 to $2.24 \mathrm{mV}$, an increase in sensor $\mathrm{CV}$ at the level of the knee from 32 to $40 \mathrm{~m} / \mathrm{s}$ (the norm is more than $40 \mathrm{~m} / \mathrm{s}$ );

- Other parameters, including intensity of muscle fiber denervation activity in the distal muscle of the leg, were unchanged (Fig. 1, Table 2).

TABLE 2. Parameters of electromyography of motor and sensory nerves of the patient's upper and lower limbs (the study conducted on 29.11.2016, 4 months after the initial examination and 5 months after ibrutinib dose reduction)

a) Motor nerve conduc on velocity (MNCV)

\begin{tabular}{|c|c|c|c|c|c|c|}
\hline$S$ mula on site & $\begin{array}{l}\text { Latency of } \\
\text { M-response, } \\
\text { ms }\end{array}$ & $\begin{array}{c}\text { Amplitude of } \\
\text { M-response, } \\
\mathrm{mV}\end{array}$ & $\begin{array}{c}\text { Dura on of } \\
\text { M-response, } \\
\text { ms }\end{array}$ & $\begin{array}{c}\text { Area of } \\
\text { M-response, } \\
\mathrm{mV} \times \mathrm{ms}\end{array}$ & $\begin{array}{c}\mathrm{MNCV} \\
\mathrm{ms}\end{array}$ & Comment \\
\hline \multicolumn{7}{|c|}{ Right m.Abductor digiti minimi, n.Ulnaris, C8-T1 } \\
\hline wrist & $4.23(\mathrm{~N}<3.0)$ & $2.44(\mathrm{~N}>6.0)$ & 8.47 & 10.3 & & \\
\hline $4 \mathrm{~cm}$ below elbow joint & 10.6 & 1.94 & 10.8 & 9.5 & $34.4(N>50)$ & \\
\hline above elbow & 14.7 & 1.99 & 11.1 & 11.0 & $27.4(\mathrm{~N}>50)$ & \\
\hline \multicolumn{7}{|c|}{ Left m.Abductor digiti minimi, n.Ulnaris, C8-T1 } \\
\hline wrist & $2.8(\mathrm{~N}<3.0)$ & $6.35(\mathrm{~N}>6.0)$ & 6.6 & 22.5 & & \\
\hline $4 \mathrm{~cm}$ below elbow joint & 7.54 & 3.68 & 10.6 & 16.5 & $44.3(N>50)$ & $\begin{array}{c}\text { Forearm Mw } \\
\text { Dispersion }\end{array}$ \\
\hline Above elbow & 11.7 & 3.08 & 8.6 & 14.2 & $26.1(\mathrm{~N}>50)$ & \\
\hline \multicolumn{7}{|c|}{ Left m.Abductor pollicis brevis, n.Medianus, C8-T1 } \\
\hline wrist & $6.03(\mathrm{~N}<3.5)$ & $3.02(N>5.0)$ & 11.9 & 14.9 & & \\
\hline elbow & 10.7 & 2.39 & 13.2 & 13.3 & $45.1(\mathrm{~N}>50)$ & \\
\hline above elbow & 13.3 & 2.41 & 12.4 & 13.5 & $45.4(\mathrm{~N}>50)$ & \\
\hline \multicolumn{7}{|c|}{ Right m.Tibialis anterior, n.Peroneus profundus, L4-S1 } \\
\hline head of $\mathrm{f}$ bular & 5.08 & $2.24(\mathrm{~N}>3.5)$ & 12.1 & 14.7 & & \\
\hline popliteal fossa & 6.56 & 1.79 & 11.4 & 11.0 & $81.0(\mathrm{~N}>40)$ & \\
\hline \multicolumn{7}{|c|}{ Right m.Abductor hallucis, n.Tibialis, L5-S1 } \\
\hline medial malleolus & & 0 & & & & \\
\hline \multicolumn{7}{|c|}{ Right m.Extensor digitorum brevis, n.Peroneus profundus, L4-S1 } \\
\hline ankle joint & & 0 & & & & \\
\hline
\end{tabular}

b) Sensor nerve conduc on velocity (SNCV)

\begin{tabular}{|c|c|c|c|}
\hline$S$ mula on site & $\begin{array}{c}\text { Latency of } \\
\text { S-response, ms }\end{array}$ & $\begin{array}{c}\text { Amplitude of } \\
\text { S-response, } \mu \mathrm{V}\end{array}$ & $\mathrm{SNCV}, \mathrm{ms}$ \\
\hline \multicolumn{4}{|l|}{ Right $\mathrm{n}$. Medianus II } \\
\hline wrist & $3.28(\mathrm{~N}<3.0)$ & $0.7(\mathrm{~N}>15.0)$ & $50.3(\mathrm{~N}>50)$ \\
\hline \multicolumn{4}{|c|}{ Right n.Peroneus superficialis, L4-S1 } \\
\hline Middle third of lower leg & & & \\
\hline
\end{tabular}

Note: M-response - motor response, S-response - sensor response, $\mathrm{CB}$ - conduc on block, N - norm, n.Medianus - median nerve, n. Ulnaris ulnar nerve, n.Peroneus profundus - deep f bular nerve, $n$.Tibialis - bial nerve, n.Peroneus superf cialis - superf cial $\mathrm{f}$ bular nerve, $\mathrm{m}$.Abductor digi minimi - the muscle abduc ng the li le $\mathrm{f}$ nger, $\mathrm{m}$.Abductor pollicis brevis - the short muscle abduc ng the thumb, $\mathrm{m}$.Tibialis anterior - anterior bial muscle, m.Abductor hallucis - the muscle abduc ng the great toe, m.Extensor digitorum brevis - the short muscle extending toes. Due to the posi ve clinical-neurophysiological dynamics, it was decided to con nue the observa on. 


\section{DISCUSSION}

Chemotherapy-induced polyneuropathy is a subacute (within 4-8 weeks) or chronic (for more than 8 weeks) polyneuritic disorders that develop during or 3-6 months after a chemotherapy course with predominance of symptoms reflecting involvement of sensory and autonomic fibers (Table 3). Their specific feature is dose- and chemotherapeutic agent-dependence, alleviation of symptoms after discontinuation of the drug that induces the disease $(2,3)$.

The group of chemotherapeutic agents with high and moderate degree of neurotoxicity is currently defined (Table 4) (4).

The exact mechanism of chemotherapy-induced types of polyneuropathy is still unclear. Nevertheless, considering various action spectrums of drugs and results of a number of pilot studies, scientists suggest the following main pathogenic drivers: disturbance of DNA cellular structure, mitochondrion and microtubules damage, axonal transport disturbance, oxidizing processes and apoptosis activation, neurotransmitter ion channel function change, etc. The result of these processes is formation of vicious mutually activating pathophysiological circles. The specified changes inevitably lead to dorsal ganglia damage, development of neuronopathy and disturbance of axon microtubular architectonics, which finally results in axonal nerve fibers degeneration (Fig. 2) $(5,6)$.

Chemotherapy-induced sensory, autonomic and sensorimotor polyneuropathies are common in the practice of clinical neurologists; the great majority of them are axonal $(2-4,20)$. The demyelinating pattern of changes is much less often revealed in the NCS of this category of patients.

Scientific literature covers few cases of development of demyelinating polyneuropathies caused by chemotherapy. In all the described cases, the cause of the complication is bortezomib (Table 4) (8-12). It is assumed that demyelinating polyneuropathies associated with bortezomib are caused by immune-mediated mechanisms. That was confirmed by morphological, neuroimaging and neurophysiological studies, as well as by clear neurologic improvement after administration of high-dosage intravenous immunoglobulin $(9,10,13)$. Development of demyelinating polyneuropathy after ibrutinib administration has not been described in scientific literature.

Ibrutinib (Imbruvica, PCI-32765) is a new-generation drug in the treatment of malignant B-lymphoproliferative diseases. It is a covalent selective inhibitor of Bruton thyroxikinase, which plays an

TABLE 3. The main clinical manifestations of chemotherapy-induced polyneuropathies, depending on the type of fibers involved (3).

\begin{tabular}{|l|l|}
\hline Injured structure & Clinical manifestations \\
\hline Peripheral ganglion & $\begin{array}{l}\text { - Loss of propriocep on and vibra on sense } \\
\text { - Sensory ataxia } \\
\text { - Pain, temperature and tac le hypoesthesia } \\
\text { - Dysesthesias } \\
\text { - Neuropathic pain } \\
\text { - Autonomic dysfunc on }\end{array}$ \\
\hline Small-diameter sensory f bers & $\begin{array}{l}\text { - Dysesthesias } \\
\text { - Allodynia } \\
\text { - Neuropathic pain } \\
\text { - Burning } \\
\text { - Paresthesias }\end{array}$ \\
\hline Small-diameter autonomic f bers & $\begin{array}{l}\text { - Intes nal mo lity disorders (cons pa on, diarrhea) } \\
\text { - Urinary reten on } \\
\text { - Blood pressure instability (including orthosta chypotension) } \\
\text { - Sexual dysfunc on } \\
\text { - Impaired swea ng, etc. }\end{array}$ \\
\hline Large-diameter sensory $\mathrm{f}$ bers of superf cial sensi vity & $\begin{array}{l}\text { - Numbness of hands and feet } \\
\text { - Paresthesias } \\
\text { - Pain and temperature hypoesthesia }\end{array}$ \\
\hline Large-diameter sensory $\mathrm{f}$ bers of deep sensi vity & $\begin{array}{l}\text { - Impaired propriocep on and vibra on sense } \\
\text { - Impaired coordina on of movements, sta cs and gait - sensory ataxia }\end{array}$ \\
\hline Motor f bers & $\begin{array}{l}\text { - Muscle weakness } \\
\text { - Awkward movements } \\
\text { - Walking disorder }\end{array}$ \\
\hline
\end{tabular}


TABLE 4. Characteristics of chemotherapeutic agents with high and moderate degree of neurotoxicity (according to Banach M. et al. 2016 (4), with alterations).

\begin{tabular}{|c|c|c|c|}
\hline Preparation & Cases of administration & Mechanism of action & Neurotoxicity \\
\hline $\begin{array}{l}\text { Pla num-based } \\
\text { drugs: cispla n, } \\
\text { carbopla } n, \\
\text { oxalipla } n\end{array}$ & $\begin{array}{l}\text { Lung, ovarian, bladder, } \\
\text { colorectal cancer, etc. }\end{array}$ & $\begin{array}{l}\text { The prepara ons bifunc onally alkylate DNA strands, inhibit } \\
\text { biosynthesis of nucleic acids, and cause cell death. At the f rst stage, } \\
\text { they inhibit the synthesis of DNA, RNA and protein; on the second } \\
\text { stage, they form metabolic products, which affect only DNA synthesis. }\end{array}$ & $\begin{array}{l}\text { Very High } \\
70-100 \%\end{array}$ \\
\hline $\begin{array}{l}\text { Taxane-containing } \\
\text { drugs: paclitaxel, } \\
\text { Abraxane, docetaxel }\end{array}$ & $\begin{array}{l}\text { Breast, ovarian, } \\
\text { prostate, lung, } \\
\text { pancreas cancer, etc. }\end{array}$ & $\begin{array}{l}\text { These drugs have a cytotoxic an mito c effect, induce anomalous } \\
\text { bundle-like arrangement of microtubules throughout the en re cell } \\
\text { cycle. }\end{array}$ & $\begin{array}{l}\text { High } \\
11-87 \%\end{array}$ \\
\hline $\begin{array}{l}\text { Thalidomide and } \\
\text { its analogues: } \\
\text { lenalidomide, } \\
\text { Revlimid, } \\
\text { Methoblas } \mathrm{n}\end{array}$ & Mul ple myeloma & $\begin{array}{l}\text { This an -angiogenic immune-modula ng drug inhibits secre on of } \\
\text { proinf ammatory cytokines (TNF- } \alpha, \mathrm{IL}-1 \beta \text {, IL- } 6 \text { and IL-12), induces } \\
\text { prolifera on of T-cells and intensif es the synthesis of IL-2 and } \\
\text { interferon }-1 \gamma \text {, активность собственных клеток-киллеров. it also } \\
\text { increases the cytotoxic ac vity of natural killer cells. }\end{array}$ & $\begin{array}{l}\text { High } \\
20-60 \%\end{array}$ \\
\hline Ixabepilone, Ixempra & Breast cancer & $\begin{array}{l}\text { The drug stabilizes the microtubule dynamics, which leads to blockade } \\
\text { of tumor cell mitosis, and, f nally, to their apoptosis and death. }\end{array}$ & $\begin{array}{l}\text { High } \\
60-65 \% \\
\end{array}$ \\
\hline Bortezomib & Mul ple myeloma & $\begin{array}{l}\text { Bortezomib is a proteasome inhibitor; it reversibly inhibits the } \\
\text { chymotrypsin-like ac vity of the } 265 \text { proteasome - a large protein } \\
\text { complex, which catalyzes cleavage of the main proteins and regulates } \\
\text { their intracellular concentra ons. That impedes proteolysis, causing } \\
\text { a complex signaling cascade inside the cell and disturbance of its } \\
\text { homeostasis, which ul mately leads to apoptosis. }\end{array}$ & $\begin{array}{l}\text { Moderate } \\
20-30 \%\end{array}$ \\
\hline $\begin{array}{l}\text { Vinca alkaloids: } \\
\text { vincris ne, } \\
\text { vinblas ne, } \\
\text { vinorelbine, } \\
\text { vindesine }\end{array}$ & $\begin{array}{l}\text { Lung, brain, bladder, } \\
\text { tes cular cancer, etc. }\end{array}$ & $\begin{array}{l}\text { These prepara ons bind to tubulin, inhibit forma on of mito c } \\
\text { spindle and stops mito c cell division at the metaphase stage. Its } \\
\text { large doses also inhibit the synthesis of nucleic acids and protein. }\end{array}$ & $\begin{array}{l}\text { Moderate } \\
\text { Up to } 20 \%\end{array}$ \\
\hline
\end{tabular}

important role in maintenance of malignant cells viability. In 2014, it was approved by the U.S. Food and Drug Administration for treatment of patients with chronic lymphocytic leucosis (14). The official instruction to the drug (the part concerning side effects) mentions development of sensory axonal neuropathy in up to $40 \%$ of cases (15).
The interrelation between ibrutinib administration and polyneuritic disturbances in our patient was evident; it was also confirmed by spontaneous improvement after the daily dose reduction. This case was characterized by the presence of the motor disturbances, which were not described previously. There were also interesting electrophysiological

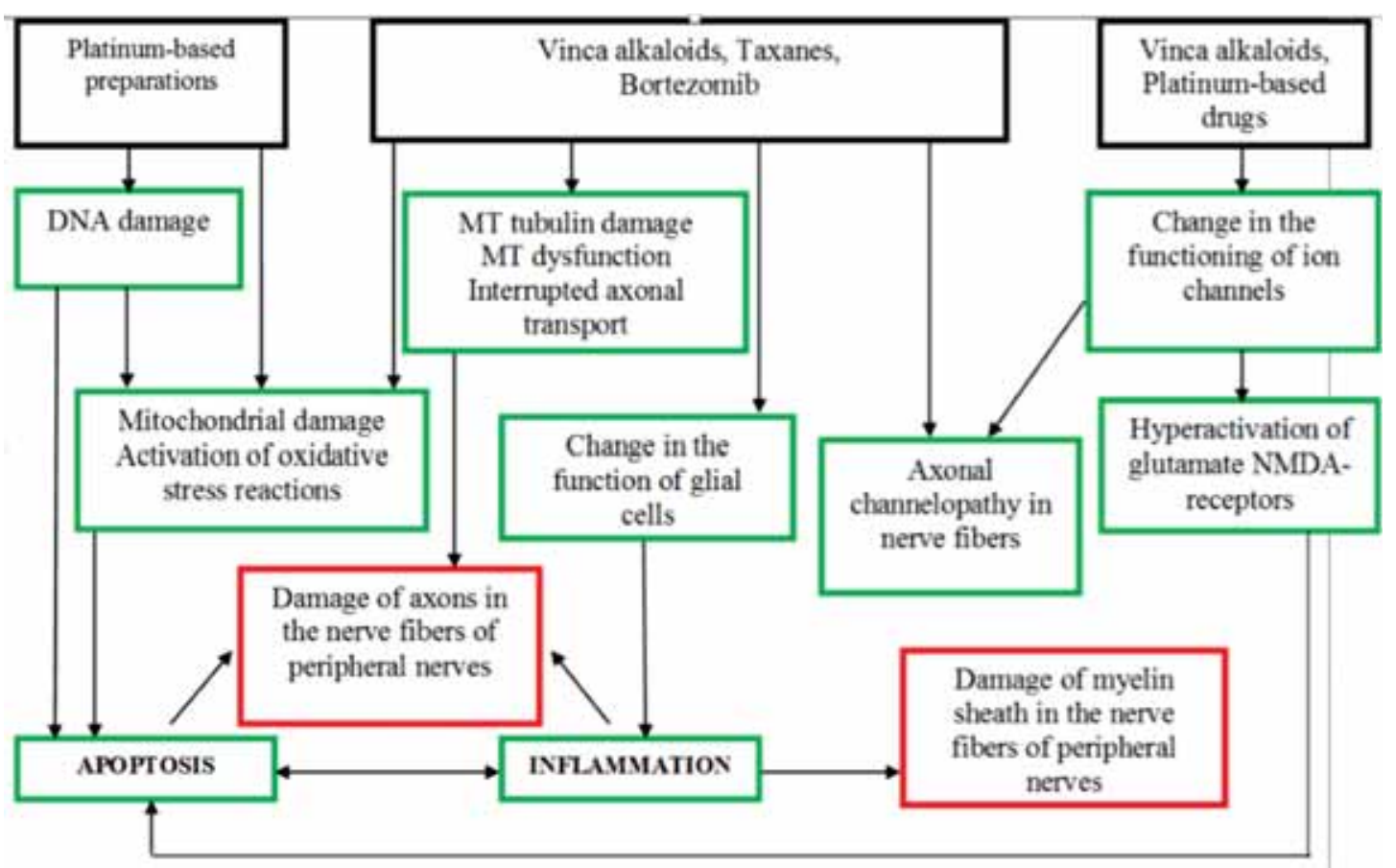

FIGURE 2. Probable pathogenic mechanism of chemotherapy-induced polyneuropathy development $(5,6)$.

Note: DNA - deoxyribonucleic acid, MT - microtubules. 
findings, requiring specification of the disease etiology: either toxic or dysimmune.

As other causes of demyelinating polyneuropathy (idiopathic, hereditary, paraproteinemic ones) were excluded in the course of examination and the ultrasonography of peripheral nerves did not reveal any changes in their structure that could be typical for an inflammatory process (16-18), toxic genesis was obvious. This allowed choosing the best tactics for the patient managing (dynamic observation after the permissible ibrutinib dose reduction) and proved the refusal from immunotherapy by intravenous immunoglobulins.

The main tactics for managing the patients with the polyneuropathies of toxic genesis after chemotherapy consists in the most possible reduction in the dose of the chemotherapeutic drug and symptomatic therapy: correction of autonomic disturbances, treatment of neuropathic pain syndrome by drugs and methods with a proved efficiency (tricyclic antidepressants, duloxetine/venlafaxine, pregabalin/gabapentin, cognitive behavioural therapy, transcranial magnetic stimulation, etc.), prescription of non-drug treatment-and-rehabilitation actions (kinesiotherapy, transdermal electroneuroand myostimulation) (21-23). Persistence or increase of neurologic disorders and considerable motor deficiency limiting self-care may require complete cancellation of chemotherapy. There is no pathogenic treatment for toxic polyneuropathies, and neurometabolic drugs showed no convincing efficiency in test trials $(4,21,22)$.

Another tactics should be used in the cases of progressing demyelinating chemotherapy-induced polyneuropathies with proven dysimmune genesis, in which it is possible to conduct a disease-modifying treatment with steroid drugs or intravenous immunoglobulin $(9,10,24,25)$. Dysimmune genesis of polyneuropathy can be clarified by means of laboratory tests (blood test for antibodies to gangliosides, electrophoresis of serum proteins and urine with immunofixation, liquor analysis for oligoclonal antibodies, etc.), instrumental examination (ultrasonography of nerves, magnetic resonance imaging of plexus with a contrast intensifier) and morphological examinations (sural nerve biopsy) tests (16-19).

\section{CONCLUSION}

The present paper is the first description of chronic demyelinating polyneuropathy developed after ibrutinib administration. It shows the differentiated approach to specify the causes of neurologic disorders in the patients undergoing chemotherapy.

Conflict of interest: none declared Financial support: none declared

\section{REFERENCES}

1. McGuire S. World Cancer Report 2014. Geneva, Switzerland: World Health Organization, International Agency for Research on Cancer, WHO Press, 2015. Adv Nutr. 2016 Mar 15; 7(2):418-9.

2. Colosimo M., Vitetta L. Chemotherapy-induced peripheral neuropathy management. J Clin Oncol. 2016 Jan 20; 34(3):154.

3. Windebank A.J., Grisold W. Chemotherapy-induced neuropathy. J Peripher Nerv Syst. 2008 Mar; 13(1):27-46.

4. Banach M., Juranek J.K., Zygulska A.L. Chemotherapy-induced neuropathies-a growing problem for patients and health care providers. Brain Behav. 2016 Oct 26; 7(1): e00558.

5. Han Y., Smith M.T. Pathobiology of cancer chemotherapy-induced peripheral neuropathy (CIPN). Front Pharmacol. 2013 Dec 18; 4:156

6. Areti A., Yerra V.G., Naidu V., Kumar A. Oxidative stress and nerve damage: role in chemotherapy induced peripheral neuropathy. Redox Biol. 2014 Jan 18; 2:289-95.

7. Van den Bergh P.Y., Hadden R.D., Bouche P., Cornblath D.R. et al. European Federation of Neurological Societies/Peripheral Nerve Society Guideline on management of chronic inflammatory demyelinating polyradiculoneuropathy: report of a joint task force of the European Federation of Neurological Societies and the Peripheral Nerve Society - First Revision. Joint Task Force of the EFNS and the PNS. J Peripher Nerv Syst. 2010 Mar; 15(1):1-9.

8. Thawani S.P., Tanji K., De Sousa E.A. et al. Bortezomib-associated demyelinating neuropathy - clinical and pathologic features. J Clin Neuromuscul Dis. 2015 Jun; 16(4):202-9.
9. Schmitt S., Goldschmidt H., Storch-Hagenlocher B. et al. Inflammatory autoimmune neuropathy, presumably induced by bortezomib, in a patient suffering from multiple myeloma. Int $\mathrm{J}$ Hematol. 2011 Jun; 93(6):791-4.

10. Ravaglia S., Corso A., Piccolo G. et al. Immune-mediated neuropathies in myeloma patients treated with bortezomib. Clin Neurophysiol. 2008 Nov; 119(11):2507-12.

11. Richardson P.G., Briemberg H., Jagannath S. et al. Frequency, characteristics, and reversibility of peripheral neuropathy during treatment of advanced multiple myeloma with bortezomib. J Clin Oncol. <https://www.ncbi.nlm.nih.gov/pubmed/16754936> $2006 \mathrm{Jul}$ 1; 24(19):3113-20.

12. Argyriou A.A., Iconomou G., Kalofonos H.P. Bortezomib-induced peripheral neuropathy in multiple myeloma: comprehensive review of the literature. Blood. <https://www.ncbi.nlm.nih.gov/pubmed/? term=Bortezomib-induced+peripheral+neuropathy+in+multiple+myel oma\%3A+a+comprehensive+review+of+the+literature> 2008 Sep 1 ; 112(5):1593-9.

13. Lees J.G., Makker P.G., Tonkin R.S. et al. Immune-mediated processes implicated in chemotherapy-induced peripheral neuropathy. Eur J Cancer. 2017 Jan 16; 73:22-29.

14. Kim E.S., Dhillon S. Ibrutinib: review of its use in patients with mantle cell lymphoma or chronic lymphocytic leukemia. Drugs. 2015 May; 75(7):769-76. 
15. Lekarstvennye preparaty $\vee$ Rossii. (Medicines in Russia). Reference book. Vidal 2017. Vidal Rus <http://www.labirint.ru/pubhouse/3547/>, 2017. Pages: 1240.

16. Vuytsik N. B., Suponeva N. A., Chechetkin A. O., Piradov M.A., Suslina Z.A. Ultrasound neuroimaging in chronic inflammatory demyelinating polyneuropathy. Annals of clinical and experimental neurology. 2014; 8(3):9-13. (in Russian)

17. Druzhinin D.S., Naumova E.S., Nikitin S.S. Ultrasound imaging of peripheral nerves in multifocal motor neuropathy and chronic inflammatory demyelinating polyneuropathy. Neuromuscular diseases. 2016; 6(1):63-73. (in Russian)

18. Vuytsik N.B., Chechetkin A.O., Pavlov E.V., Klushnikov S.A., Illarioshkin S.N. Clinical-sonographic and neurophysiological comparisons in hereditary motor and sensory neuropathy. Annals of clinical and experimental neurology. 2014; 8(4):9-14. (in Russian)

19. Suponeva N.A., Naumova E.S., Gnedovskaya E.V. Chronic inflammatory demyelinating polyneuropathy at adults: principles of diagnostics and first line therapy. Neuromuscular Diseases. 2016; 6(1):44-53. (in Russian)

20. Suponeva N.A., Belova N.V., Zaitseva N.I. et al. Small fiber neuropathy. Annals of Clinical and Experimental Neurology. 2017; 11(1): 73-79. (in Russian)

21. Pachman D.R., Barton D.L., Watson J.C., Loprinzi C.L. Chemotherapy-induced peripheral neuropathy: prevention and treatment. Clin Pharmacol Ther. 2011 Sep; 90(3):377-87.
22. Seretny M., Currie G.L., Sena E.S. et al. Incidence, prevalence, and predictors of chemotherapy-induced peripheral neuropathy: A systematic review and meta-analysis. Pain. 2014 Dec; 155(12):246170.

23. Chervyakov A.V., Poydasheva A.G., Korzhova Yu. E. et al. Rhythmic transcranial magnetic stimulation in neurology and psychiatry / S.S. Korsakov Journal of Neurology and Psychiatry. 2015; 115(12):7-18. (in Russian)

24. Suponeva N.A., Grishina D.A. Intravenous high-dose immunotherapy: practical recommendations for use in the treatment of neurological disimmune diseases. Neuromuscular Diseases. 2015; 5(4):16-23. (in Russian)

25. Suponeva N.A., Piradov M.A. Vnutrivennaya ummunoterapia v nevrologii (Intravenous immunotherapy in neurology). Goryachaya liniya-Telecom Moscow, 2013, 312 p. ISBN 978-5-9912-0324-1. (in Russian)

26. Olney R.K, Lewis R.A, Putnam T.D., Campellone J.V. Jr. American Association of Electrodiagnostic Medicine <https://www.ncbi.nlm.nih. gov/pubmed/? term=American\%20Association $\% 20$ of\%20Electrodiagnostic $\% 20$ Medicine $\% 5 B$ Corporate $\% 20$ Author $\% 5 D>$. Consensus criteria for the diagnosis of multifocal motor neuropathy. Muscle Nerve. 2003 Jan; 27(1):117-21. 